\title{
TTR
}

Traduction, terminologie, re?daction

\section{Sherry Simon. Le Trafic des langues : traduction et culture dans la littérature québécoise. Montréal, Boréal, 1994, 224} pages.

\section{Rainier Grutman}

Volume 8, numéro 1, 1er semestre 1995

Orientations européennes en traductologie

URI : https://id.erudit.org/iderudit/037209ar

DOI : https://doi.org/10.7202/037209ar

Aller au sommaire du numéro

Éditeur(s)

Association canadienne de traductologie

ISSN

0835-8443 (imprimé)

1708-2188 (numérique)

Découvrir la revue

Citer ce compte rendu

Grutman, R. (1995). Compte rendu de [Sherry Simon. Le Trafic des langues :

traduction et culture dans la littérature québécoise. Montréal, Boréal, 1994, 224

pages.] TTR, 8(1), 288-291. https://doi.org/10.7202/037209ar d'utilisation que vous pouvez consulter en ligne.

https://apropos.erudit.org/fr/usagers/politique-dutilisation/ 


\section{Sherry Simon. Le Trafic des langues : traduction et culture dans la littérature québécoise. Montréal, Boréal, 1994, 224 pages.}

Dans son dernier livre, Sherry Simon étudie les tentatives de plusieurs auteurs québécois pour dépasser le vieil antagonisme franco-anglais, pour déconstruire le réflexe identitaire et pour amorcer une authentique réflexion sur l'altérité. La traduction mentionnée dans le sous-titre de son essai s'insère donc dans un cadre plus large. À l'affut de la différence culturelle inscrite dans le texte, plus qu'à la recherche d'une illusoire équivalence entre un original et sa traduction, Simon s'intéresse aux aspects «traductionnels» propres à la création dans un Québec multiculturel, dont la littérature est «hantée par une fracture linguistique» (p. 25) entre la forme et la substance. Pour classer des textes aux «repères linguistico-culturels» incertains, elle parle d'un processus de «traduction inachevée» qui, en soulignant «l'interdépendance de l'ici et l'ailleurs» (pp. 28-29), rendrait flexibles les frontières communautaires et caduques les certitudes identitaires.

Après un rappel historique du discours québécois sur la traduction où l'auteure renoue avec ses anciennes préoccupations (cf. 
l'Inscription sociale de la traduction au Québec, 1989), elle nous convie à faire la connaissance d'une bonne dizaine de «trafiqueurs» québécois. En leur milieu - il occupe littéralement le centre du livre - trône Abraham Moses Klein, ce poète et essayiste montréalais des années 1930 et 1940 chez le mélange des idiomes anglais, français, yiddish, hébraïque et latin produit «esthétique de la fusion» (p. 101). Tout à la fois traducteur de poésie juive (C. N. Bialik, J. I. Segal) et poète imbu de lettres anglaises tant classiques (Milton) que modernes (Joyce, Pound), ce chantre de la diaspora nord-américaine établit un constant dialogue entre le passé et le présent. À lui seul, il paraît réunir les versants créatif et textuel du «trafic» des langues: ses textes, polyphoniques en plus d'être polyglottes, ne mettent-ils pas en œuvre "une poétique de la traduction inachevée» (p. 95)? Ceci mérite d'autant plus d'être souligné que la plupart des auteurs examinés par Simon se limitent à l'une des deux possibilités.

D'un côté, il y a ceux qui, tels Jacques Brault, Nicole Brossard, Jacques Poulin, Daniel Gagnon, esquissent une poétique de la traduction, parfois à leur corps défendant. Leurs traductions sont en général achevées au point d'améliorer le texte qu'elles transposent: Brault réécrit les poèmes qu'il pirate, les personnagestraducteurs de Brossard et de Poulin corrigent les originaux, Gagnon écrit deux fois son roman. (En investissant le traducteur d'una autorité traditionnellement réservée au seul auteur, ces exemples portent de l'eau au moulin de ceux et celles qui considèrent une version traduite comme une répétition non point parasitaire mais créatrice de nouveauté.) À cela s'ajoutent les adeptes de la traduction inachevée, qui entrelardent leurs fables de xénismes, résonances exotiques ou de sonorités étrangères. Sur un mode alternativement joyeux et tragique, la Québécoite de Régine Robin et Babel, prise deux de Francine Noël interrogent le rapport postmoderne au(x) langage(s) dans la ville cosmopolite. La même tension créatrice entre le contact et la conflit interlinguistique est maintenue dans les pièces «immigrantes» de Marco Micone et de Robert Lepage, avec cette différence, capitale, que l'auteur dramatique vise un contact direct avec le public. Il s'ensuit que «le théâtre bilingue met en langues sa propre thématique» et s'adresse à un public capable d'enjamber «la barrière linguistique» (p. 163). 
Ce qui nous ramène à la traduction, car il ne saurait y avoir d'opération de cet ordre sans obstacle à franchir. Il est d'ailleurs frappant de constater à quel point le travail de Sherry Simon privilégie le régime métaphorique de l'espace. Tantôt, la frontière rend possible la reproduction d'une langue «dans une aire linguistico-culturelle» (p. 112); tantôt, il est question d'expériences qui «chevauchent les frontières normalement attribuées à la traduction, à l'écriture, et au commentaire» (p. 179) ou encore d'un "glissement des sols qui autrefois [...] donnaient forme et consistance» (p. 183) aux identités. C'est là, bien sûr, une façon de récupérer, en les subvertissant, les images chères au nationalisme tellurique. Ce geste rend insuffisamment compte pourtant de la place centrale qu'occupe le «trafic» des langues. Pris au pied de la lettre, celui-ci consisterait à faire passer les idiomes clandestinement d'un territoire à l'autre, franchissant la frontière et détruisant d'illusoires unités culturelles. Certes, il y a belle lurette que dialectologues et sociolinguistes se sont aperçus de l'absence de réelles frontières linguistiques. Mais en attendant que les littéraires - y compris les comparatistes, égratignés au passage par Simon (p. 180) - et les historiens de la traductions arrivent au même constat, voici un livre qui inscrit la conscience et le dépassement des frontières au centre de sa problématique.

Beau titre, le Trafic des langues laisse toutefois intacte l'aura négative dont sont entourés la traduction, le plurilinguisme et l'alternance des codes. En effet, faisant référence à des pratiques illicites, «trafic»", "trafiquer», etc., souffrent d'évidentes connotations péjoratives. Ce n'est pas par hasard qu'un essai classique sur la prostitution s'intitule «The Traffic in Women'» (1911): 1'anarchisteféministe Emma Goldman y dénonce l'exploitation des femmes et cloue au pilori l'hypocrisie puritaine des Américains face au «White Slave Traffic». À la lumière de ce texte, on pourrait croire que Simon dénoncerait la réification des idiomes en littérature, alors que

1. Ce texte fournit un intertitre à Barbara Godard, "Translating (With) the Speculum», TTR IV(2), 1991, in S. Simon, dir. «Traduire la théorie», p. 93. 
tout le contraire est vrai. Sa revendication du droit au trafic linguistique - «[1]e texte plurilingue, pénétré d'effets de traduction, met en question les contours mêmes de ce que nous appelons traduction» (p. 178) - rejoindrait plutôt les thèses exposées par la critique américaine Margery Sabin dans The Dialect of the Tribe (1987). Aux yeux de celle-ci, la modernité anglaise ressemble à une vaste opération de contrebande (smuggling), dans la mesure où ses auteurs cultivent une ambivalence à l'égard de la tradition «nationale» et incorpore volontiers des données étrangères dans leur écriture. Sabin n'hésite pas à comparer James, Joyce, D. H. Lawrence et Beckett à des voyageurs qui, en rentrant chez eux, décident de ne pas déclarer certaines marchandises à la frontière. Plus même, cette pratique les aurait dotés d'une conscience linguistique extrêmement aiguë: «'English', as an inherited language, still more as a culture or social community, is very far from a clearly declared value for them» (Sabin, 1987, p. 7).

Or, loin d'être dénoncée, la contrebande littéraire est célébrée ici parce qu'elle permet aux écrivains modernes de se défaire du carcan des conventions classiques et de s'abreuver à d'autres sources. Chez Sherry Simon, qui convoque le livre de Sabin et le commente dans des termes fort louangeurs (pp. 117, 145, 198200), la métaphore du trafic appliquée aux «effets de traduction» reçoit un traitement comparable. Figure de la transgression, le texte plurilingue brouille les pistes en soulignant les points communs entre création et traduction. Une fois abolies ou mieux redessinées les frontières artificielles entre différentes langues et cultures, l'activité traduisante est projetée à l'intérieur des textes mêmes, où elle «n'aboutit pas toujours à un résultat homogène mais [...] se confronte en permanence à l'inachevé» (p. 181). Reste évidemment la question de savoir comment on procédera pour «trafiquer», au Québec ou ailleurs, une fois que les frontières ont été ouvertes et que les interdits ont été levés.

Rainier Grutman Université d'Ottawa 